\title{
Short Teacher Responses in the EFL Classroom: A Corpus- Approach Assessment
}

\author{
Iosif Keselman, Yulia Yakovleva \\ Orel State University named after I.S. Turgenev
}

Correspondence concerning this article should be addressed to Iosif Keselman, Orel State University named after I.S. Turgenev, 95, Komsomolskaya st., Orel region, Orel, 302026, Russian Federation.

E-mail: josef.kes@gmail.com

\begin{abstract}
Teacher's positive feedback in the form of immediate succinct response is an indispensable motivational factor crucial to students' oral production and classroom participation. The present study was intended to assess the range and authenticity of teacher responses used by a number of Russian teachers of English in everyday classroom interactions. The study adopted theCorpus Approachas a reference tool to verify the research data against a Corpus-driven evidence that isto examine and assess the authenticity of the most frequent responses given by the study participants (21 practising EFL teachers working in Orel, Russia, most of whom are graduates of Orel State University, andwhose teaching experience ranges from 11 to 25 years). The results indicated that the phrases the teachers used in the classroom differed from those native speakers use in similar authentic environment. The analysis revealed that the teachers did not resort to clear and concise positive reinforcement often enough to stimulate the students' engagement. In addition, a finite list of highly authentic TRs was recommended for more frequent use in ordinary EFL classrooms and among would-be English teachers. Overall, both teachers in the field and trainee teachers need to be more informed on how and in what particular way to encourage their students' classroom participation.
\end{abstract}

Keywords: foreign language teaching, feedback, authenticity, corpus approach, classroom English

\section{Introduction}

\section{Positive Feedback in EFL Classroom}

Feedback is one of the essential elements of both learning and teaching. Ur (2009) defines feedback as "information that is given to the learner about his or her performance of a learning task, usually with the objective of improving this performance" (p.242).

The topic of feedback provision has gained considerable attention recently. Scholars all agree that teacher's feedback influences teaching and learning. It has been empirically identified as being among the most important instructional practices for improving student learning (Gentrup, Lorenz, Kristen, \& Kogan, 2020). The classroom feedback discourse is seen an important part of classroom interactive discourse (Liu, Liu, \& Zhang, 2021), and the analysis of its pragmatic functions can help provide guidance for EFL teachers on how to increase classroom interactivity.

Feedback can be corrective and focus a learner's attention on errors, or non-corrective, in the form of praise or encouragement (Kerr, 2017). According to Ellis and Shintani (as cited in Kerr, 2017), praising students for good performance is believed to increase motivation and to foster positive attitudes to learning. Unfortunately, teachers rarely, if at all, draw attention to students getting things right while, as Ur (2012) points out, "a student who produces an accurate bit of language (particularly if he or she is avoiding a very common mistake) deserves to be noticed and praised" (p. 91). For the purposes of this study, explicit positive feedback provides the focal interest as an effective way in which the teacher could motivate students, foster their self-confidence and promote participation in the EFL classroom. We restrict our consideration to a specific type of such feedback, namely, to instances of the teacher's short utterances made in response to a student's classroom verbal activity, henceforth TR. Such utterances differ from other teachers' positive responses in that they only express the 
teacher's encouraging attitude without distracting the student's, and the other participants', attention from the issue at hand. They usually consist of one word, sometimes, more, but their role in the classroom processes is significant.

Giving feedback is part of "teacher-learner interaction/communication", which occurs in every EFL classroom and is believed to be central to all classroom activity (Hughes, 1989; Walsh, 2011). As many researchers maintain, classroom interaction is consequential to learners' language learning and development and may directly affect foreign language acquisition. It has been reported that "teacher communication behaviour as one of the situational (environmental) factors may influence learners' willingness to communicate" (Heidari,Moradian, \&Arani, 2017, p.84). Thus, in order to teach well, teachers need to acquire what Walsh calls Classroom Interactional Competence (CIC) and defines as "teachers' and learners' ability to use interaction as a tool for mediating and assisting learning" (Walsh, 2011, p.31). Levels of interactional competence vary hugely from teacher to teacher, with some teachers being very adept at managing interaction and thus maximising learning opportunities, and others falling short of it.

This difference is especially evident among Non-Native English Speaking Teachers (NNESTs). In the light of widely adopted communicative language teaching (CLT) authentic communication in the target language is seen as one of the main ways to implement authenticity in a foreign language classroom (Thompson, 1996).

\section{English Corpora and Teacher Education}

Most teacher education programmes in the Russian Federation, either pre- or in-service, pay little or no attention to classroom communication and interaction, thus leaving Russian NNESTs to their own devices in this respect. While it may take years of teaching experience to realize its centrality to foreign language teaching and learning, there is a number of teaching aids available that describe literally any classroom situation and help verbalize any classroom procedure (Gardner \& Gardner, 2000' Hughes, 1989²; Hughes, Moate, \&Raatikainen, 20113; Slattery \& Willis, 2014 ${ }^{4}$ ). Besides, fairly recently corpus linguistics has been making "outstanding contributions to the fields of second language research and teaching" (Bennett,2010, p.2). One of the major characteristics of the Corpus Approach, as Bennett stated nearly a decade ago, is that it is "empirical, analysing the actual patterns of language use in natural texts" (2010, p.7). Since corpora are composed of various communication acts extracted from textbooks, newspapers, academic papers, lectures, phone conversations, transcripts of classroom interaction, radio and TV shows, they are to be understood as composed of authentic language. The Corpus Approach can help us answer some questions related to Classroom English and equip NNESTs with a valuable tool to enhance their CIC. In general, the issue of pedagogical applications of corpus linguistics and developing teachers' corpus literacy in language education has been repeatedly addressed (Abdel Latif, 2021).

Against this backdrop, the present study aims to assess the authenticity of immediate positive feedback provided by Russian NNESTs in EFL classroom implementing corpus-based approach. The corpus-assisted studies of short positive teacher responses in classroom interaction are under-documented.

\section{Literature Review}

\section{Positive Feedback in Language Learning}

"Encouraging students to speak is an important part of classroom work, and it's important to find ways to encourage all students to take part” (Scrivener, 2012, p. 179).

"The classroom situation is a genuine social environment which allows the meaningful situational use of the language" (Hughes, 1989, p.6). In normal face-to-face communication such responses as 'uh-huh' or head

\footnotetext{
Gardner, B., \& Gardner, F. (2000). Classroom English. Oxford University Press.

2 Hughes, G.S. (1989). A handbook of classroom English. Oxford University Press.

3 Hughes, G., Moate, J., \& Raatikainen, T. (2011). Practical classroom English. Oxford University Press.

4 Slattery, M., \& Willis, J. (2014). English for primary teachers: A handbook of activities and classroom English. Oxford University Press.
} 
nodding convey agreement, show that the message has been received and understood, and can be seen as forms of feedback. "People speak most when they feel really listened to" (Scrivener, 2012, p. 180). So, it only seems natural that teachers in the EFL classroom "should always try to model good listening skills, including appropriate body language, nods, gestures and confirming expressions (e.g. 'Right', 'Uh-huh')” (Kerr, 2017, p.9). By doing so teachers show interest in, and can respond to, the ideas that their students express.

Genuine comments can act as positive reinforcement of the student's speaking production. As Lewis \& Hill recommend, "show your reaction to what students say" (Lewis \& Hill, 1992, p. 13). As they maintain further, if the teacher is surprised, shocked, curious or doubtful, he should show it in his general reaction, in what he says, and in how he says it. Other students are encouraged to show their reactions too. "Such reacting develops an important language skill - the active role of the listener in a conversation - and makes both the language and your lessons more alive for students" (ibid).

Richards and Lockhart (2007) point out that in language classrooms, feedback on a student's spoken language may be a response either to the content of what a student has produced or to the form of an utterance. Among a variety of strategies available in giving feedback on content they mention acknowledging a student's correct answer by saying, for example, "Good", "Yes, that's right", or "Fine”, and praising when the teacher compliments a student for an answer by saying "Yes, an excellent answer" (p. 189).

Along with the above-mentioned, supportive feedback has a potential to reduce anxiety. It holds true even for students with lower anxiety levels. It has been well-established that we all learn best when we are mentally relaxed, and teachers should "always try to generate a relaxed atmosphere, inviting rather than demanding, a response" (Lewis \& Hill, 1992, p. 20). Said and Weda (2018) reported that "students' anxiety can be reduced in all levels of language learning by implementing good atmosphere and relaxed situation to attract students' involvement in the language learning process" (p.28). It should be noted that feedback may serve not only to let learners know how well they have performed but also to "increase their motivation and build a supportive classroom climate" (Richards \& Lockhart, 2007, p.189). The results of the multilevel analysis showed that a positive atmosphere is related to fostering willingness to communicate as well as enjoyment. It also has potential for reducing anxiety among students (Khajavy,MacIntyre, \&Barabidi, 2018).

Positive reinforcement from the teacher is an important motivational factor. The study that explored demotivational teaching practices in EFL classroom setting ranked the teacher who does not encourage students to participate in the classroom activity number one among other factors that could cause students' demotivation (Weda, 2018). According to Christenbury and Kelly "behaviours such as maintaining eye contact, nodding, making affirming verbal comments or sounds, or asking a student to continue with additional clarifying remarks are all ways to encourage more participation” (as cited in Tofade, Elsner, \&Haines, 2013).

The results of Liu, Liu, \& Zhang (2021) show that though general supportive feedback discourse in the classroom accounts for a small proportion of all positive feedback, it promotes the interaction between teachers and students to a large extent. General supportive feedback usually uses interjections, such as "Yeah", "Um", "Uhhuh", which have no exact meanings but implicit pragmatic meanings, demonstrating teachers' approval, satisfaction, or doubt.

The findings of another study that explored the similarities and differences between native and non-native English language teachers suggest that though both groups provided immediate feedback, NNELTs, unlike NELTs, provided implicit feedback mostly on production. It could be characterised as restated, delayed, and specific to the point. NELTs resorted mainly to "pronunciation correction through teacher-modeling" (Alfehaid, 2019, p.376).

\section{Linguistic Corpora and Language Teaching}

This study focuses on one type of teacher responses (TRs), namely short, explicit, positive assessments. In terms of their structure, they are single utterances of one-word or a short-phrase or a-single-sentence strings. They are short so that their occurrence may not change the vector of the classroom activity at the moment. They are positive so that the student feels confident and encouraged. The studies mentioned above highlight 
the importance of TRs that express confirmation and encouragement for classroom communication and participation. The scope of authentic usage of TRs is determined with the help of English Language corpora.

Considerable attention has been given to an important notion of discourse markers (DM). Our particular attention has been attracted by studies of DMs used by teachers of English in the classroom (Ding, \& Wang, 2015; Zorluel Özer, \& Okan, 2018). The subject of this study, TR, may be considered to be a kind of DM, but only in a very broad sense. They are much more restricted in discourse function and much more specific pragmatically. They serve different discursive functions. They act as attention-getters (e.g. 'okay', 'oh', 'so', 'now'), signal imminent turn-taking (e.g. 'okay', 'so', 'now'), mark the agreement or response to the students (e.g. 'yes', 'right', 'yeah', 'okay'). They are indicative of attitudes, evaluations, and other dimensions of the classroom environment. In essence, DMs indicate the active construction of discourse as well as responsive and engaged listenership by the teachers (Ding, \& Wang, 2015). The main role of DMs is to give students encouragement and show positive assessment of their speech. Another difference between the DMs discussed in the mentioned studies and the TRs treated here is that the body of studied DMs was predetermined, borrowedfrom works on discourse analysis. The list of TRs studied in the present paper was derived from teachers' verbal behavior in the classroom and noted by the instructed trainee teachers, on the basis of the notions of positive assessment and encouragement.

Special mention should be made about the use of corpora notions and techniques in the two DMs studies. They follow a rather popular strategy of compiling a DIY small corpus based on the texts under consideration and analyzing properties of a number of words (usually their frequency and collocability). Traditionally, this is done by viewing concordancing lines. The concordancing is done with the help of a special tool, AntConc. The typical drawback of such small corpora is that the results gained from using them can show little more than properties of those texts; the frequency of words, for instance, cannot be evaluated as high or low without comparison with other, more comprehensive, data. Whatever a researcher may call a collection of 20 or 90 thousand words (tokens), it would not make it a "real" corpus. Conversely, comparison of frequencies, raw or relative, found in such collection with frequencies supplied by large annotated corpora might cause valuable ideas about the behavior of words in certain types of discourse.

Linguistic corpora have been in the field for nearly sixty years. At the present moment their uses in theoretical and applied linguistics are many and varied. Their use for pedagogical purposes, especially for foreign language teaching, has become a matter of common knowledge. A considerable body of literature is now available, from profound studies of teaching principles and corpora use (Campoy-Cubillo, Belles-Fortuno, \&Gea-Valor, 2010; Flowerdew, 2014; Hunston, 2002; Leech, 1997; O’Keeffe \& Farr, 2003) to corpora-aided assessment of teaching materials (Kiziltan\&Baydal, 2018) to assessing learners' proficiency (Callies, Diez-Bedmar, \&Zaytseva, 2014) to reports of finding solutions to classroom problems (Allen, 2011; Btoosh, 2019; DeSutter, Cappelle, DeClercq,Loock\&Plevoets,2017;McEnery \& Xiao, 2005) to descriptions of attempts to make students use corpora in the classroom (Read, 2016) $)^{5}$. It is natural that in dealing with classroom language the idea of implementing corpora advantages should have presented itself. In this study, we use English language corpora as a reference tool for assessing the authenticity of the NNESTs' TRs against native speakers' preferences for using similar phrases. We proceed from the widely accepted assumption that linguistic corpora are composed of real language as it is used by native speakers/writers. To the best of our knowledge, such kind of treating short TRs has not been described in professional literature.

\section{Research Questions and Hypothesis}

The major purpose of this study was to examine a number of NNESTs' use of oral encouragement in the classroom, to find out how many and what TRs are most frequent among EFL teachers in Orel, Russia, and whether their preferred forms of oral encouragement represent actual patterns of language use in natural texts typically produced by native English speakers. Specifically, the following research questions were posed:

1. Does the repertoire of TRs used by NNESTs meet the criteria of authenticity and linguistic variability?

2. What TRs are the most recurrent in English corpora and must be included into teacher education programmes to enhance pre-service EFL teachers' CIC?

\footnotetext{
${ }_{5}$ Read, D. (2016). I'm an EAP teacher and I hate Corpus Linguistics. http://learningtechnologiesineap.org/im-an-eap-teacher-and-i-hate-corpuslinguistics/
} 
According to our assumption the following hypothesis was put forward:

There is significant difference in the range and choice of TRs used by the NNESTs involved in the study and those TRs that the English language corpora suggest.

\section{Materials and Methods}

\section{Participants}

Participants in the classroom communication are usually a teacher and students. In this research, a group of 19 would-be teachers, third-year students of the English Department, Institute of Foreign Languages, Orel State University (OSU), when undergoing practical pre-service training in the city schools and non-language OSU departments, were assigned a task to observe and write down the practising English teachers' assessing responds. There were 56 English lessons by 21 teachers visited and monitored. All the teachers had more than 10 years of experience of teaching English as a foreign language in high schools and universities in Russia.

\section{Materials}

The main body of analysed material consisted of the TRs collected by the trainee teachers in the way described above. Also significant were certain examples from a number of special handbooks of classroom English.

\section{Classroom English Handbooks}

All of the consulted books are written to assist teachers in improving their confidence in speaking English in the classroom to carry out practical day-to-day management of classes. The handbooks vary greatly in the number of phrases of relevance to the current study (see Table 1). However, it can be accounted for by the difference in their target audiences.

\section{Table1}

Number of classroom phrases expressing encouragement and confirmation in Handbooks for NNESTs

\begin{tabular}{lc}
\hline \multicolumn{1}{c}{ Handbook } & Number of phrases \\
\hline A Handbook of Classroom English (Hughes, 1989) & 75 \\
Classroom English (Gardner \& Gardner, 2000) & 16 \\
Practical Classroom English (Hughes et al., 2011) & 175 \\
English for Primary Teachers (Slattery \& Willis, 2014) & 8 \\
\hline
\end{tabular}

"English for Primary Teachers" is a handbook for those who teach English to children aged 4-12, whose language proficiency is understandably low. Its aim is to expand teachers' range of classroom language to manage each basic activity with short and simple instructions and give Young Learners valuable experience of English in use. "Classroom English" is addressed to NNESTs who have little or no training, and few resources to work with in the hope that when their confidence and proficiency increase, they will add to their repertoire of classroom language.

"A Handbook for Classroom English" is intended for trainee teachers and teachers in the field, who by working systematically through its materials will acquire a wide range of accurate and idiomatic phrases. "Practical Classroom English" is for NNESTs who work with teenagers and young adults at secondary and post-secondary levels. The book contains some phrases that are straightforward and easy, whereas others are more complex and are for use mainly with advanced learners.

Thus, as can be seen from the foregoing, the differences in the number of phrases expressing oral encouragement and confirmation in the handbooks are based on the three main criteria: the students' age, the level of students' language proficiency, the level of the teacher's language proficiency. 
All four books contain fairly comprehensive lists of classroom phrases. However, their sources are different. The material for "A Handbook of Classroom English" was collected on the basis of about two hundred hours of English lessons in Finland, and twenty-five hours of teaching in an English comprehensive school. In the case of "Practical Classroom English", the book's foundations were laid by the authors' thirty years of experience, observation reports on trainee English teachers' lessons as well as transcribed classroom recordings from Austria, Belgium, Finland, Germany, Japan, Korea, Spain, and Taiwan. The rationale for the choice ofphrases in the book by Bryan and Felicity Gardner is not disclosed to its readers. The authors' prime intention was to choose the simplest ways of saying things that could be used with beginners. The basis of the book "English for Primary Teachers" is the recordings of both native and non-native primary teachers' lessons around the world sent to the authors from Japan, Turkey, Spain, Italy, etc. Thus, though presumably almost all of the books boast real language from real lessons, none of them meets the criterion of authenticity understood here as naturally occurring English in native speakers' communication.

\section{English Language Corpora}

A number of dependable corpora of English are free to be found on the Web. The most prominent and widely used is the collection of corpora created by Mark Davies at the Brigham Young University (https://www.englishcorpora.org/).The most popular one is the Corpus of Contemporary American (COCA) that comprises at the present time 560 million words. Its SPOKEN register exceeds 100 million words, which is more than the whole contents of the celebrated BNC (the British National Corpus, the original variant; work is in progress to build a British corpus of everyday conversations as an extension of the BNC, The Spoken BNC2014(Love,Dembry, Hardie, Brezina, \& McEnery, 2017). The chief shortcoming of COCA from this work's standpoint is that it mirrors only the American variant of the language. Fortunately, Davies (2019) published two more remarkable corpora, the TV Corpus and the Movie Corpus, that are multinational (US, Canada, Britain, Ireland, Australia, New Zealand, India et al.) and, obviously, spoken. The size of the two corpora is considerable (Movie - 200 mil, TV - 325 mil), which ensures statistically dependable results of the searches. For more detail, see Davis (2021).

In the case of strings, the corpora can find only those that are recurrent in a considerable degree, which is to be understood as evidence for their co-occurring stability. Even intuitively, it would be unfeasible to expect longish sentences like 'There is nothing wrong with your answer' (Hughes, 1989) to be frequent enough in common conversation. There would not be enough instances of it in a corpus of 325 or 200 mil words. This limitation, however, should not present a real challenge to this study as the TRs under discussion are short recurrent utterances as defined earlier.

The corpora created by Mark Davies allow searches for words and word strings that have different language statuses. The search in COCA, a 560-million-words corpus of American English, yields 1075 instances of 'Good' as a separate sentence/utterance (=TR) while the overall frequency of 'good' in COCA is 510181. This means that, on the average, the word is used about 911times per million words being one of the most frequent words in English (it ranks 65 in the two-billion-words Oxford English Corpus as evidenced in Wikipedia (https:// en.wikipedia.org/wiki/Most_common_words_in_English). As for the utterance 'Good', the frequencies for registers show its predominant use in conversations: SPOKEN - 588, FICTION - 434, MAGAZINE - 32, NEWSPAPER - 16, ACADEMIC - 5.

\section{Procedure}

The following steps were taken to accomplish the purpose of the study during the research process.

First, the researchers chose 19 advanced level prospective English teachers who were to undergo their compulsory pre-service training in schools and non-language university departments in Orel, Russia. In order to obtain the relevant data, they were asked to record all forms of oral encouragement used by practising teachers during English classes. The TRs as written down by the students were collected immediately after the attended lesson and the list of noted TRs was compiled.The teachers were not informed about what pre-service trainees were asked to record and there was no instruction to the teachers on using any specific types of positive feedback given by the researchers. All classroom activity is expected to be observed and recorded by prospective teachers as part of their professional training. The permission to do so is granted on the basis of the standard contractual agreement between OSU and other educational institutions in Orel. The teachers were later informed about the specific aims and interim results of the research. Then the recorded items were collected and summarised in tables. Next, the collected data were compared with the lists of classroom phrases 
included in the teaching aids and preliminary observations concerning individual teachers' manner of giving positive feedback were made.The most frequent of the collected TRs were then looked up in the TV Corpus. Some instances of TRs were also checked in the Movie Corpus and the COCA. The final stage was analysing the data in order to find reasonable answers to the research questions.

\section{Data Analysis}

In answering the research questions, the researchers analysed the range and authenticity of the TRs. The analysis of the data was deployed in two stages. During the first stage, the collected TRs were compared against those that the handbooks for NNESTs suggest and preliminary observations concerning individual teachers' manner of giving positive feedback were made. To ensure the reliability of the research procedure, the explanatory instructions were given to the trainee teachers collecting the TRs, which were consecutively accepted as valid by each researcher and later the lists were sifted through collaboratively by both. At the second stage the most frequently used of the recorded TRs were looked up in the English corpora to confirm the hypothesis and draw the final conclusion.

\section{Results}

\section{Collected TRs}

The collected data of the current study show that the NNESTs used different numbers of TRs ranging between 4 and 33 (see Table 2). The recorded TRs revealed no recurrent inaccuracies since all the teachers in the study had received formal university training in the target foreign language. The teachers used English as a medium for classroom management purposes employing short positive assessments in the process.

\section{Table 2}

Range of TRs

\begin{tabular}{lc}
\hline Teacher & Number of TRs \\
\hline Teacher 1 & 33 \\
Teacher 2 & 5 \\
Teacher 3 & 25 \\
Teacher 4 & 8 \\
Teacher 5 & 8 \\
Teacher 6 & 8 \\
Teacher 7 & 15 \\
Teacher 8 & 15 \\
Teacher 9 & 4 \\
Teacher 10 & 20 \\
Teacher 11 & 14 \\
Teacher 12 & 18 \\
Teacher 13 & 12 \\
Teacher 14 & 14 \\
Teacher 15 & 10 \\
Teacher 16 & 15 \\
Teacher 17 & 6 \\
Teacher 18 & 9 \\
Teacher 19 & 14 \\
Teacher 20 & 23 \\
Teacher 21 & 25 \\
\hline
\end{tabular}


However, it should be noted that the overall variability of phrases used to acknowledge students' responses is limited, with some teachers (T2, T9, T17) having a scanty repertoire of classroom phrases. It was particularly noticeable in the secondary school classrooms. Though all the teachers in the study claimed commitment to CLT, some of them failed to create additional opportunities for genuine communication and interaction in their classroom. This may turn out to be an even more flawed strategy in the presence of prospective English teachers who attend lessons during pre-service training. Such behaviour may be detrimental to their own students' progress since "the classroom situation is a genuine social environment which allows 'the meaningful situational use of the language', and that its communicative potential is closer to real interaction than is often assumed" (Hughes, 1989, p.6). Classroom language "allows for almost unlimited repetition in a natural context: classroom instructions are part and parcel of every lesson, so there is no need to invent contexts of use. In this way the language gradually becomes absorbed unconsciously by the students" (Gardner \& Gardner, 2000, p.1).

The teachers chose different forms of expressing positive feedback. The collected and analysed TRs reveal noticeable differences in the preferred ways of encouragement and confirmation. As Walsh (2006) maintains "teachers do employ their own particular 'classroom idiolect': an individual way of talking that is normally based on their personal conversational style" (as cited in Walsh, 2011, p.7).

Certain individual TRs promoted the following inductive reasoning. Most teachers in the study avoided giving affective feedback with only one teacher (T1) explicitly demonstrating emotional involvement in the process by such TRs as 'Great!', 'Bravo!', 'That's amazing!', 'How impressive!'. Showing natural authentic reaction to a student's production arguably increases the speaker's and other students' interest and participation. Conversely, the observed avoidance of it may lead to increased formality and artificiality highly undesirable in the EFL classroom.

Another potentially counterproductive tendency was observed when the teachers used responses such as 'I've been thinking about the same', 'I share your opinion' (T3), 'That's exactly what I was looking for' (T7). Though being communicatively justifiable under most classroom circumstances, they seem to suggest the singularity of the correct answer.

Among the recorded TRs there were cases when the teacher's reaction was expressed in a far less tactful and delicate way than the desired effect could suggest. Such TRs as 'I know you are initiative but let others think too' (T9), 'It's much better this time but there are too many careless slips', 'Shows some improvement' (T7), 'Now you have figured it out' (T3) imply criticism of the student's behaviour. Without being specific, they do not fully perform the function of corrective feedback and may only discourage students from speaking. As Kerr (2017) points out 'teachers need to handle feedback sensitively so as not to affect students' willingness to speak' (p.10).

All in all, the 21 NNESTs whose lessons were attended to collect data for the current study used about one hundred different TRs. To make valid conclusions, only the TRs which were found in the repertoire of three and more teachers were analysed in respect to their authenticity. Among the twenty TRs listed in Table 3 some ('Absolutely', 'True', 'That's a good job') are not included in any of the consulted Classroom English handbooks.

\section{Table 3}

TRs most commonly used by the teachers

\begin{tabular}{lc}
\hline \multicolumn{1}{c}{ TR } & Number of teachers \\
\hline That's it & 10 \\
That's right & 8 \\
Well done & 8 \\
Good & 8 \\
Exactly & 8 \\
Exactly so & 6 \\
Right & 6 \\
Right you are & 6
\end{tabular}




\begin{tabular}{lc}
\hline \multicolumn{1}{c}{ TR } & Number of teachers \\
\hline Yes & 6 \\
Absolutely & 6 \\
True & 6 \\
Good job & 6 \\
That's a good job & 4 \\
Have another try & 4 \\
Okay! & 4 \\
Nice & 4 \\
Yes, you are right & 4 \\
That's the way & 4 \\
Uh-huh & 4 \\
Correct & 4 \\
\hline
\end{tabular}

\section{TRs and Linguistic Corpora}

Table 4 presents the results of the TRs searches in the TV Corpus of spoken English. It has 325 million words that come from TV shows in North America (US/CA - 265.8 mil), in Britain and Ireland (UK/IE - 53.2 mil), in Australia and New Zealand (AU/NZ - 5.7 mil) and others (MISC - 0.3 mil). In addition to the TRs from Table 3, several items were included in the search from those recommended in Hughes (1989), Hughes et al.(2011), Gardner \& Gardner (2000).

\section{Table 4}

The TV Corpus

\begin{tabular}{|c|c|c|c|c|c|}
\hline TR & Frequency & Per mil & US/CA: FREQ/per ml & UK/IE: FREQ/per ml & AU/NZ: FREQ/per ml \\
\hline That's it & 10140 & 31.20 & $8200 / 30.85$ & $1693 / 31.85$ & $199 / 38.71$ \\
\hline That'stheway & 85 & 0.26 & $46 / 0.17$ & $24 / 0.45$ & $14 / 2.72$ \\
\hline Right & 42040 & 129.35 & $30154 / 113.45$ & $10571 / 198.8$ & $1096 / 213.21$ \\
\hline Right you are & 108 & 0.33 & $50 / 0.19$ & $54 / 1.02$ & $4 / 0.78$ \\
\hline That's right & 4217 & 12.98 & $35.59 / 13.39$ & $599 / 11.27$ & $18 / 8.54$ \\
\hline Good & 33447 & 102.92 & $27511 / 103.50$ & $4997 / 94.01$ & 766/ 149.01 \\
\hline Goodjob & 2038 & 6.27 & $1968 / 7.40$ & $56 / 1.05$ & $9 / 1.75$ \\
\hline That's a goodjob & 13 & 0.04 & $0 / 0.00$ & $/ 0.00$ & $0 / 0.00$ \\
\hline Well done & 2864 & 8.81 & $1677 / 6.31$ & $1066 / 20.06$ & $107 / 20.81$ \\
\hline Very well done & 47 & 0.14 & $30 / 0.11$ & 17 / 0.32 & 00 \\
\hline Okay & 129881 & 399.63 & $127120 / 478.25$ & $1608 / 30.25$ & $516 / 100.38$ \\
\hline$O K$ & 26833 & 82.56 & $14783 / 55.62$ & 9831 / 184.96 & 2065 / 401.71 \\
\hline Okay fine & 2 & 0.01 & $2 / 0.01$ & 00 & 00 \\
\hline Fine & 17808 & 54.79 & $16044 / 60.36$ & $1454 / 27.36$ & 209 / 40.66 \\
\hline Very fine & 7 & 0.02 & $6 / 0.02$ & $1 / 0.02$ & 00 \\
\hline Exactly & 8991 & 27.66 & $7126 / 26.81$ & $1643 / 30.91$ & $173 / 33.65$ \\
\hline Exactly so & 4 & 0.01 & $3 / 0.01$ & $1 / 0.02$ & $0 / 0.00$ \\
\hline Nice & 4621 & 14.22 & $4170 / 15.69$ & $381 / 7.17$ & $53 / 10.31$ \\
\hline
\end{tabular}




\begin{tabular}{|c|c|c|c|c|c|}
\hline TR & Frequency & Per mil & US/CA: FREQ/per ml & UK/IE: FREQ/per ml & AU/NZ: FREQ/per ml \\
\hline That's nice & 1392 & 4.28 & $1168 / 4.39$ & $201 / 3.78$ & $19 / 3.70$ \\
\hline That's very nice & 161 & 0.50 & $149 / 0.56$ & $10 / 0.19$ & $2 / 0.39$ \\
\hline Yes & 47175 & 145.15 & $33620 / 126.49$ & $12079 / 227.25$ & 1084 / 210.87 \\
\hline Yes, youareright & 149 & 0.46 & $85 / 0.32$ & $59 / 1.11$ & $3 / 0.58$ \\
\hline Uh-huh & 27 & 0.08 & $21 / 0.08$ & $5 / 0.09$ & $1 / 0.19$ \\
\hline Correct & 943 & 2.90 & $657 / 2.47$ & $228 / 4.29$ & $53 / 10.31$ \\
\hline That's correct & 227 & 0.70 & $189 / 0.71$ & $35 / 0.66$ & $1 / 0.19$ \\
\hline That's perfectly correct & 1 & 0.00 & $0 / 0.00$ & $1 / 0.02$ & $0 / 0.00$ \\
\hline True & 1560 & 4.80 & $1281 / 4.82$ & $201 / 3.78$ & 47 / 9.14 \\
\hline Verytrue & 79 & 0.24 & $51 / 0.19$ & $26 / 0.49$ & $2 / 0.39$ \\
\hline Absolutely & 4005 & 12.32 & $3196 / 12,02$ & $717 / 13.49$ & $76 / 14.78$ \\
\hline Haveanothertry & 0 & 0.00 & 0 & 0 & 0 \\
\hline Very good & 2785 & 8.57 & $1921 / 7.23$ & $760 / 14.30$ & $77 / 14.98$ \\
\hline That's very good & 108 & 0.33 & $77 / 0.29$ & $29 / 0.55$ & $2 / 0.39$ \\
\hline Good for you! & 1659 & 5.10 & $1477 / 5.56$ & $150 / 2.82$ & $26 / 5.06$ \\
\hline Yes, that's right - good & 0 & 0 & 0 & 0 & 0 \\
\hline Perfect & 3594 & 11.06 & $3201 / 12.04$ & $331 / 6.23$ & $49 / 9.53$ \\
\hline Magnificent & 88 & 0.27 & $63 / 0.24$ & $18 / 0.34$ & $4 / 0.78$ \\
\hline Fabulous & 163 & 0.50 & $132 / 0.50$ & $29 / 0.55$ & $1 / 0.19$ \\
\hline Sensational & 17 & 0.05 & $15 / 0.06$ & $1 / 0.02$ & $1 / 0.19$ \\
\hline Excellent & 3596 & 11.06 & $2588 / 9.74$ & $906 / 17.05$ & $74 / 14.40$ \\
\hline That's excellent & 28 & 0.09 & $12 / 0.05$ & $16 / 0.30$ & $0 / 0.00$ \\
\hline
\end{tabular}

As evident from Table 4, the short TRs are much more frequent than their lengthened variants. 'Right' is about four times more frequent than 'That's right' and nearly three times so than 'Yes, you are right'. See also strings with good, exactly, excellent, nice, yes, true, well, etc.

'Right you are' is the least frequent of the processed strings with right which are commonly used in all dialects. The TVC shows that its use is rather limited, perhaps because of its sounding very emotional and being much more common in the British variant.

Some longer strings ('Yes, that's right - good', 'Have another try') have been treated by the corpus as not recurrent enough to be considered, in their own right, as separate speech units.

In most cases the relative frequency (per mil), henceforth RF, of units in the UK/IE sections is higher than that in the US/CA section. This can be explained by the statistically unbalanced distribution of the corpus texts between the Sections/Dialects. North American TV texts in the corpus are nearly five times greater than those from Britain (265.8 and 53.2 mil words respectively). In most cases, American RF is close to the general RF of the item while that of the British section is somewhat greater, see e.g. 'That's it', 'Right', 'Exactly', 'Absolutely'. In the cases where American RF is greater than British RF it is reasonable to believe that the response is considerably more common in North America than in Britain, see e.g. 'Good job', 'Fine', 'Nice', 'That's nice', 'True', Good for you', 'Perfect'.

The positively assessing responses 'Perfect' and 'Excellent' have nearly the same Raw frequency (3594 and 3596 respectively) and identical Relative frequency (11.06 per mil) in the TVC. However, the Sections/Dialect data show that 'Perfect' is more common in AmE and 'Excellent' in BrE and the less common 'That's excellent' in BrE exceeds AmE even in Raw frequency. 


\section{Discussion}

Oral classroom communication has long been and has continued to be the object of empirical and theoretical inquiry led by researchers and teachers. The studies have investigated the provision and effectiveness of positive feedback for foreign language acquisition, underpinning the thesis that short and simple phrases help to move a lesson forward fluently and create a motivating atmosphere central to successful language learning. The current study supports these shared conclusions, but examines another and more pragmatic aspect of Classroom English, to wit assessing short teacher's responses (TRs) from the point of view of authentic, reallife language use.

The lack of previous research focusing on corpus analysis of TRs prevents us from engaging in a traditional discussion. As suggested in Literature Review, TRs are considered to be an indispensable part of the EFL classroom procedure. Nevertheless, to the best of our knowledge, a consistent attempt has not been made to study the actual 'grass-root' facts of using, teaching and learning the TRs. Our modest study showed certain limitations in the actual state of the art, at least in the limited area of a middle-size Russian city. Yet, we consider the relevant literature and the preliminary data reported in the current study to be modest contribution to the field. The research findings may also lead to some considerations regarding the teaching process.

As Yang (2011) states, educational research on DMs in classroom discourse is mainly restricted to second / foreign language learners, and there is an obvious gap in literature examining DMs in teacher talk. A substantial body of research has been devoted to the study of DMs with an emphasis on the learner use in an English as A Foreign Language (EFL) with very few exceptions such as Zorluel Özer \& Okan (2018), Ding \& Wang (2015). The present study also investigates teachers' verbal behavior in the EFL classroom.

The described classroom observations of the teachers in the field indicated that they did not give enough positive feedback on the students' correct speech and thus limited potential learning outcomes for them. This conclusion is in consonance with that of Liu, Liu, and Zhang (2021), who found that general supportive feedback can greatly facilitate the interaction between teachers and students, since it is capable of not only expressing participation, acceptance, and recognition, but also implying that the conversational turn has yet to be finished, thus encouraging the student to continue speaking.

By following a process of recording and analysing their own classroom communication, foreign language teachers can study their own teaching behaviour - the authenticity, range and frequency of classroom phrases that they use to encourage learners and confirm their answers and its effect on learners' classroom participation. Special handbooks of classroom English are advisable to extend the area of operation of their classroom English and advance NNESTs' CIC. Since handbooks vary in the level of complexity and idiomaticity, the choice of a handbook has to be determined by the students' age and proficiency in English. Earlier researchers have made similar claims. Comparable to our study, Ding and Wang's study (2015) underpinned the necessity for nonnative English teachers to reflect on and monitor their own use of discourse markersin classroom interaction through recording and transcribing some of their own lessons, further compiling their own corpus of English teaching, and using corpus tools to analyse their own use of discourse markers.

The English language corpora are an effective means to assess the authenticity of language use. However, we certainly cannot be rigidly denying usage of any of the considered TRs on the grounds of their infrequent occurrence in the corpus texts. Corpora do not 'decide' what correct usage is and what is not. We can only interpret the corpora data in terms of relative frequencies of occurrence. This interpretation may be relevant for our recommendations regarding the choice of materials to be learned. Looking at Table 4 we can see that some of the TRs used by practising teachers are not in common use by native English speakers ('Exactly so', 'That's a good job', 'That's the way', 'Uh-huh', 'Right you are', 'Yes, you are right'). Likewise, some of the recommendations in the consulted teaching aids on Classroom English proved to be far less recurrent among native speakers ('Very well done', 'Very fine', 'That's perfectly correct', 'Magnificent', 'Sensational', 'Fabulous', 'That's excellent'). Conversely, such TRs as 'Absolutely', 'True', and 'Good job', which were frequently used by the NNESTs and which were involved in the study, were not included in the handbooks, but the corpus study revealed their wide use by native speakers. 
The results of our study appear to support the study hypothesis on the significant difference in the range and choice of TRs used by the NNESTs and TRs suggested by the corpora. Comparable to our study, Zorluel Özer and Okan's (2018) study results revealed that Turkish teachers of English significantly underused discourse markers in classroom interaction compared to native teachers. However, in the study investigating the use of DMs by native and Hong Kong teachers of English in primary and secondary schools, Ding \& Wang (2015) found that local EFL teachers in general used more DMs than native EFL teachers, though marking a variation between the primary and secondary school settings. While native teachers tended to use more DMs in primary schools, Hong Kong teachers used more DMs in secondary schools. The differences may be attributed to the differences in the contexts of the three studies and more importantly, the nature of corpora assistance.

Finally, the results of the research may be important for raising the awareness of university instructors who are involved in professional training of pre-service EFL teachers since, as already stated in Hughes (1989), "foreign language teachers in particular require linguistic training aimed at the classroom situation" (p.5).

\section{Implications for teacher education}

The findings of this study have several implications for EFL educators and teachers in Russia. We strongly believe that teacher programmes in Russia should incorporate training in CIC to enhance future EFL teachers' professional competence and their learners' command of English.

During their undergraduate and graduate studies future EFL teachers need to be exposed to authentic language used in real-life situations including an English classroom situation. Degree, so to speak, of authenticity in which different classroom phrases, including TRs, may vary is substantial. Regular exposure of would-be teachers to more authentic Classroom English is deemed more imperative than in any other audience. Such TRs as 'That's it', 'Right', 'Okay', 'Fine', 'Exactly', 'Absolutely', 'Perfect', and 'Excellent' are examples of highly authentic language use (see Table 4) and are expected to be more recurrent in EFL classrooms, whereas less typical, from a native's standpoint, TRs are recommended to be put to use with due caution. Educators, teacher trainers, practising and future EFL teachers are advised to get hold of English corpora as an indispensible practical tool to achieve the desired level of authenticity to service their classroom interaction. This recommendation is in line with Abdel Latif (2021) who reported growing interest in developing teachers' corpus literacy to popularize the use of corpora in language education.

\section{Conclusion}

The study focused on NNESTs' verbal ways of expressing positive feedback on a student's spoken language the range and authenticity of TRs they used to confirm and encourage their students' oral production.

The teacher's immediate succinct response (TR) to the student's speech production may not be as informative as a detailed assessment thereof, but it has the same communicative value in that it shows the teacher's involvement and attitude. It is essential that the TRs characterize the teacher as a competent and fair-minded instructor. They are much more frequent in the classroom, though possibly less instructive and detailed, than longer, more developed assessment expressions. They may also show, to some extent, the teacher's linguistic competence if used appropriately. This fact is consistent with the study by Hughes et al. (2011), who referred to mastering classroom phrases as one of 'the core linguistic skills' that helped teachers to work effectively in the classroom.

From the students' perspective, the TRs may have various functions. By showing the teacher's attitude a TR supports the student's communicative bond with the teacher and their conversational activity. A TR may encourage the student to pursue speaking on the subject or, conversely, it may mark off the end of a classroom episode and the possibility for a change of the speaker.

Through recording, it was found out that the teachers used a limited repertoire of TRs. The Classroom English handbooks for NNESTs suggest varied, yet not exhaustive lists of similar phrases. Both the most frequent of the recorded TRs as well as those suggested by the books were looked up in a dependable English corpus to find the most recurrent and thus more authentic ways of reacting to students' oral activity in EFL classrooms. 
The present study takes the first step in examining the range and authenticity of an aspect of classroom language used by NNESTs (short TRs expressing confirmation and encouragement). Employing the Corpus Approach enhances the assessment of the TRs authenticity. It seems reasonable to believe that further research using an identical or similar research design and implemented with regard to phrases typical of other EFL classroom situations may be practically and theoretically productive.

Due to the limitations concerning the number of participating teachers, variable levels of teachers' professional competence, and interminable process of enhancing the present corpora, the findings of the current study cannot be extrapolated to all the teaching contexts.However, the authors hope that the collected data can contribute to raising metalinguistic awareness ofboth practising and prospective EFL teachers regarding their Classroom English.

We believe that the findings have pedagogical implications that are relevant to EFL teacher education in the Russian Federation. If would-be EFL teachers are made aware of, and are exposed to, the most authentic ways of giving positive feedback, they will noticeably improve their professional skills and knowledge.

\section{Conflicts of interest}

The authors declare that they have no conflicts of interest.

\section{References}

Abdel Latif, M. (2021). Corpus literacy instruction in language teacher education: Investigating Arab EFL student teachers' immediate beliefs and long-term practices. ReCALL, 33(1), 34-48. https://doi.org/10.1017/ S0958344020000129

Alfehaid, A. (2019). Teaching ESP and general English: Similarities and differenced between native-and nonnative-English-Speaking teachers in a Saudi tertiary context. The Asian EFL Journal, 23(3.4), 352-381.

Allen, D. R. (2011). Lexical bundles in learner writing: An analysis of formulaic language in the ALESS learner corpus. Komaba Journal of English Education, 1, 105-127.

Bennett, G.R. (2010). Using corpora in the language learning classroom: Corpus linguistics for teachers. University of Michigan Press.

Btoosh, M. A. (2019). Tense and aspect in the academic writing of Arab L2 learners of English: A corpus-based approach. Journal of Language and Education, 5(2), 26-47. https://doi.org/10.17323/jle.2019.7769

Callies, M., Díez-Bedmar, M. B., \& Zaytseva, E. (2014). Using learner corpora for testing and assessing L2 proficiency. In P. Leclercq, H. Hilton, \& A. Edmonds (Eds.), Measuring L2 proficiency: Perspectives from SLA (pp. 71-90). Multilingual Matters.

Campoy-Cubillo, M. C., Belles-Fortuno, B., \&Gea-Valor, M. L. (2010). (Eds.) Corpus-based approaches to English language teaching. Continuum.

Christenbury, L., \& Kelly, P.P. (1983). Questioning: A path to critical thinking. National Council of Teachers of English.

Cobb, T., \& Boulton, A. (2015). Classroom applications of corpus analysis. In D. Biber, \& R. Reppen (Eds.), Cambridge handbook of English Corpus Linguistics (pp. 478-497). Cambridge University Press.

Davis, M. (2021) The TV and movies corpora: Design, construction, and use. InternationalJournal of Corpus Linguistics, 26(1), 10 - 37: https://doi.org/10.1075/ijcl.00035.dav

DeSutter, G., Cappelle, B., DeClercq, O., Loock, R., \& Plevoets, K. (2017). Towards acorpus-based, statistical approach to translation quality: Measuringand visualizing linguistic deviance in student translation. LinguisticaAntverpiensia, New Series: Themes in Translation Studies, 16, 25-39.

Ding, R., \& Wang, L. (2015). Discourse markers in local and native English teachers' talk in Hing Kong EFL classroom interaction: A corpus-based study. International Journal of Language and Linguistics, 2(5), 65-75.

Ellis, R., \& Shintani, N.(2013). Exploring language pedagogy through second language acquisition research. Routledge.

Flowerdew, L. (2014). Learner corpus research in EAP: Some key issues and future pathways. English Language and Linguistics, 20(2), 42-60. https://doi.org/10.47216/literacytrek.791664

Gentrup, S., Lorenz, G., Kristen, C., \& Kogan, I. (2020). Self-fulfilling prophecies in the classroom: Teacher 
expectations, teacher feedback and student achievement. Learning \& Instruction, 66, 1-17. https://doi. org/10.1016/j.learninstruc.2019.101296

Gilquin, G., Granger, S., \&Paquot, M. (2007). Learner corpora: The missing link in EAP pedagogy. Journal of English for Academic Purposes, 6(4), 319-335.

Heidari, F., Moradian, N., \& Arani, D.K. (2017). Investigating the relationship between willingness to communicate with teacher communication behavior and learning style among Iranian EAP Students. The Asian ESP Journal,13(1), 77-109. https://doi.org/10.3390/ijerph17165995

Hunston, S. (2002). Corpora in Applied Linguistics. Cambridge University Press.

Keck, C. (2013). Corpus Linguistics in language teaching. In C. A. Chapelle (Ed.), The encyclopedia of Applied Linguistics. Blackwell Publishing. https://doi.org/10.1002/9781405198431.wbeal0256

Kerr, P. (2017). Giving feedback on speaking.Cambridge University Press.

Khajavy, G., MacIntyre, P., \&Barabadi, E. (2018). Role of the emotions and classroom environment in willingness to communicate: Applying doubly latent multilevel analysis in second language acquisition research. Studies in Second Language Acquisition, 40(3), 605-624. https://doi.org/10.1017/S0272263117000304

Kiziltan, N., \& Baydal, D. (2018). A corpus analysis of the ighth Graders' textbook. Journal of the Institute of Social Sciences, 22, 285-302. https://doi.org/10.9775/kausbed.2018.020

Leech, G. (1997). Teaching and language corpora: A convergence. In A. Wichmann, S. Fligelstone, T. McEnery, \& G. Knowles (Eds.), Teaching and language corpora (pp. 1-23). Longman.

Lewis, M., \& Hill, J. (1992). Practical techniques for language teaching. Language Teaching Publications.

Liu,Y., Liu, X., \& Zhang, Y. (2021). A pragmatic study on teachers' feedback in EFL classroom in China. English language teaching, 14(5), 109-123. https://doi.org/10.5539/elt.v14n5p109

Love, R., Dembry, C., Hardie, A., Brezina, V., \&McEnery, T. (2017) The spoken BNC2014 designing and building a spoken corpus of everyday conversations. International Journal of Corpus Linguistics, 22(3), 319 - 344. https:// doi.org/10.1075/ijcl.22.3.02lov

McEnery, A. \& Xiao, R. (2005). Help or help to: What do corpora have to say? English Studies, 86(2), 161-187. https://doi.org/10.1080/0013838042000339880

O’Keeffe, A., \& Farr, F. (2003). Using language corpora in initial teacher education: Pedagogic issues and practical applications. TESOL Quarterly, 37(3), 389-418. https://doi.org/10.2307/3588397

Paquot, M. (2010). Academic vocabulary in learner writing: From extraction to analysis. Continuum.

Richards, J. C., \& Lockhart, C. (2007). Reflective teaching in second language classrooms. Cambridge University Press.

Said, M. M., \&Weda, S. (2018). English language anxiety and its impacts on students' oral communication among Indonesian Students: A case study at Tadulako University and Universitas Negeri Makassar. TESOL International Journal, 13(3), 21-30.

Scrivener, J. (2012). Classroom management techniques. Cambridge University Press.

Thompson, G. (1996). Some misconceptions about communicative language teaching. ELT Journal, 50(1), 9-15. https://doi.org/10.1093/elt/50.1.9

Tofade, T., Elsner, J., \& Haines, S. T. (2013). Best practice strategies for effective use of questions as a teaching tool. American Journal of Pharmaceutical Education, 77(7), 155. https://doi.org/10.5688/ajpe777155

Ur, P. (2009). A course in language teaching: Practice and theory. Cambridge University Press.

Ur, P. (2012). A course in language teaching. Cambridge University Press.

Walsh, S. (2006). Investigating classroom discourse. Routledge.

Walsh, S. (2011). Exploring classroom discourse: Language in action. Routledge.

Weda, S. (2018). Demotivational teaching practices in EFL classroom: Perceptions of English among Indonesian learners. The Asian EFL Journal Quarterly, 20(6), 399-413.

Yang, S. (2011). Investigating discourse markers in pedagogical settings: A literatüre review. ARECLS, 8, 95-108.

Zorluel Özer, H., \& Okan, Z. (2018) Discourse markers in EFL classrooms: A corpus-driven research. Journal of Language and Linguistic Studies, 14(1), 50-66. 